\title{
Nanorestart: Nanomaterials for the restoration of works of art
}

\author{
P. Baglioni*, D. Chelazzi and R. Giorgi
}

Cultural Heritage $(\mathrm{CH})$ represents a fundamental societal, ethical and economical resource, and a driver for education and social inclusion. To grant these benefits, however, $\mathrm{CH}$ assets need to be preserved and accessible. In particular, the conservation of modern and contemporary works of art requires advanced solutions at the cutting edge of modern chemistry and material science. Works from this era often display mixed media and materials derived from the industry that were not conceive to last long, as well as substrates with enhanced sensitiveness to water and organic solvents. Just to mention few examples, restoring modern/contemporary painted art can prove challenging when it comes to remove soiling deposited on the paint surfaces, especially in the case of works that are not varnished; the canvasses of the paintings can also become fragile by oxidative and acid-catalyzed degradation reactions; besides, tapes and adhesives on contemporary artifacts are difficult to remove owing to degradation processes and to the intrinsic sensitiveness of paper, inks and dyes; finally, outdoor sculptures and mural paintings are exposed to the progressively more adverse conditions caused by concerning climate changes.

In response to these challenges, the EU funded H2020 NANORESTART project (NANOmaterials for the REStoration of works of ART) developed nano- and advanced functionalized materials to ensure long-term protection and security of modern/contemporary $\mathrm{CH}$, taking into account environmental and human risks, feasibility and materials costs. The newly developed tools and materials

\footnotetext{
*Correspondence: piero.baglioni@unifi.it

Consorzio Interuniversitario Per Lo Sviluppo Dei Sistemi a Grande Interfase (Center for Colloid and Surface Science), CSGI, and Chemistry Department, University of Florence, Via della Lastruccia 3, Sesto Fiorentino, 50019 Florence, Italy
}

represent a breakthrough in cultural heritage and conservation science, and focus on: (i) tools for controlled cleaning, such as highly-retentive gels for the confinement of cleaning fluids based on "green" surfactants and solvents; (ii) the strengthening and protection of surfaces by using nanocontainers, nanoparticles and supramolecular systems/assemblies; (iii) nanostructured substrates and sensors for enhanced molecules detection; (iv) evaluation of the environmental impact and the development of security measures for long lasting conservation of cultural heritage. Within the project the industrial scalability of the developed materials has been demonstrated.

NANORESTART involved 27 partners from 11 countries, between 2015 and 2018. In a holistic approach to conservation, the project gathered centers of excellence in the field of synthesis and characterization of nanomaterials, world leading chemical Industries and SMEs operating in R\&D, and International and European centers for conservation, education and museums. Such centers assessed the new materials on modern/contemporary artifacts in urgent need of conservation, and disseminated the knowledge and the new nanomaterials among conservators on a worldwide perspective. The new solutions, based on green chemistry, have been used to restore masterpieces by Pablo Picasso, Jackson Pollock, Roy Lichtenstein, Eva Hesse, Giorgio de Chirico, Lucio Fontana, Jean Dubuffet, and others. Extensive dissemination and training on the new products were carried out, both in the EU and worldwide, and some of the project products are already available on the market.

In this collection we group a selection of ten papers to illustrate the highlights of the projects. The selected papers are mainly related (but not limited) to the conservation of easel paintings, as the latter represent one of the most iconic classes of $\mathrm{CH}$ objects worldwide.
Springer Open

(c) The Author(s) 2021. This article is licensed under a Creative Commons Attribution 4.0 International License, which permits use sharing adaptation, distribution and reproduction in any medium or format, as long as you give appropriate credit to the original author(s) and the source, provide a link to the Creative Commons licence, and indicate if changes were made. The images or other third party material in this article are included in the article's Creative Commons licence, unless indicated otherwise in a credit line to the material. If material is not included in the article's Creative Commons licence and your intended use is not permitted by statutory regulation or exceeds the permitted use, you will need to obtain permission directly from the copyright holder. To view a copy of this licence, visit http://creativeco mmons.org/licenses/by/4.0/. The Creative Commons Public Domain Dedication waiver (http://creativecommons.org/publicdomain/ zero/1.0/) applies to the data made available in this article, unless otherwise stated in a credit line to the data. 
An inclusive review article [1] reports on up-to-date advances on oil painting cleaning, discussing models to predict swelling or solubility of varnishes and paints, and proposing a framework for experimental and theoretical investigations into solvent transport in oil paints. Recent developments in solvent- and water-based cleaning formulations are also outlined.

Three papers [2-4] present then case studies where newly developed cleaning systems, based on retentive hydrogels, were used to remove soiling or detrimental varnishes from the surface of masterpieces by Pablo Picasso, Roy Lichtenstein and Eva Hesse. The Picasso case study involved the evaluation of recently developed gels made of polyvinyl alcohol (PVA) "twin-chain" polymer networks (TC-PNs), which were combined with an oil-in-water $(\mathrm{o} / \mathrm{w})$ nanostructured fluid (NSF) for the removal of a non-original varnish and wax layers from the surface of Picasso's "L'Atelier" (1928, Peggy Guggehnheim Collection, Venice) [2]. An extensive physicochemical characterization of the combined TC-PNs-NSF system clarified that the fluid is partially free to diffuse through the network, but also interacts with the gel walls; during the cleaning, the dynamics of the fluid at the gelartifact interface are controlled by the osmotic balance among the interconnected pores of the gel. These features provided space- and time-controlled cleaning action, allowing the removal of the varnish and wax layers, and restoring the integrity of this masterpiece without risks for the original paints (Fig. 1). Moving to another iconic work, Roy Lichtenstein's Whaam! (1963, Tate London) had accrued a layer of soiling deposited over almost 50 years of continuous display, which was affecting the aesthetic look of this masterpiece. The paper by Bartoletti et al. [3] outlines the design and execution of an optimal cleaning strategy for what came in as a highly challenging intervention. Starting with technical and historical investigation on the original artifact's materials, the process involved iterative steps following a decision-making approach, which eventually comprised the evaluation of several established and novel cleaning systems tested on representative mock-ups. The optimized cleaning strategy included the use of PVA-based TC-PNs uploaded with tailored aqueous solutions, leading to controlled and homogeneous removal of the soiling (Fig. 2), and marked the first successful treatment in the history of this Lichtenstein painting. A similar systematic approach and iterative evaluation was followed for the cleaning of Eva Hesse's sculpture Addendum (1967, Tate Collection

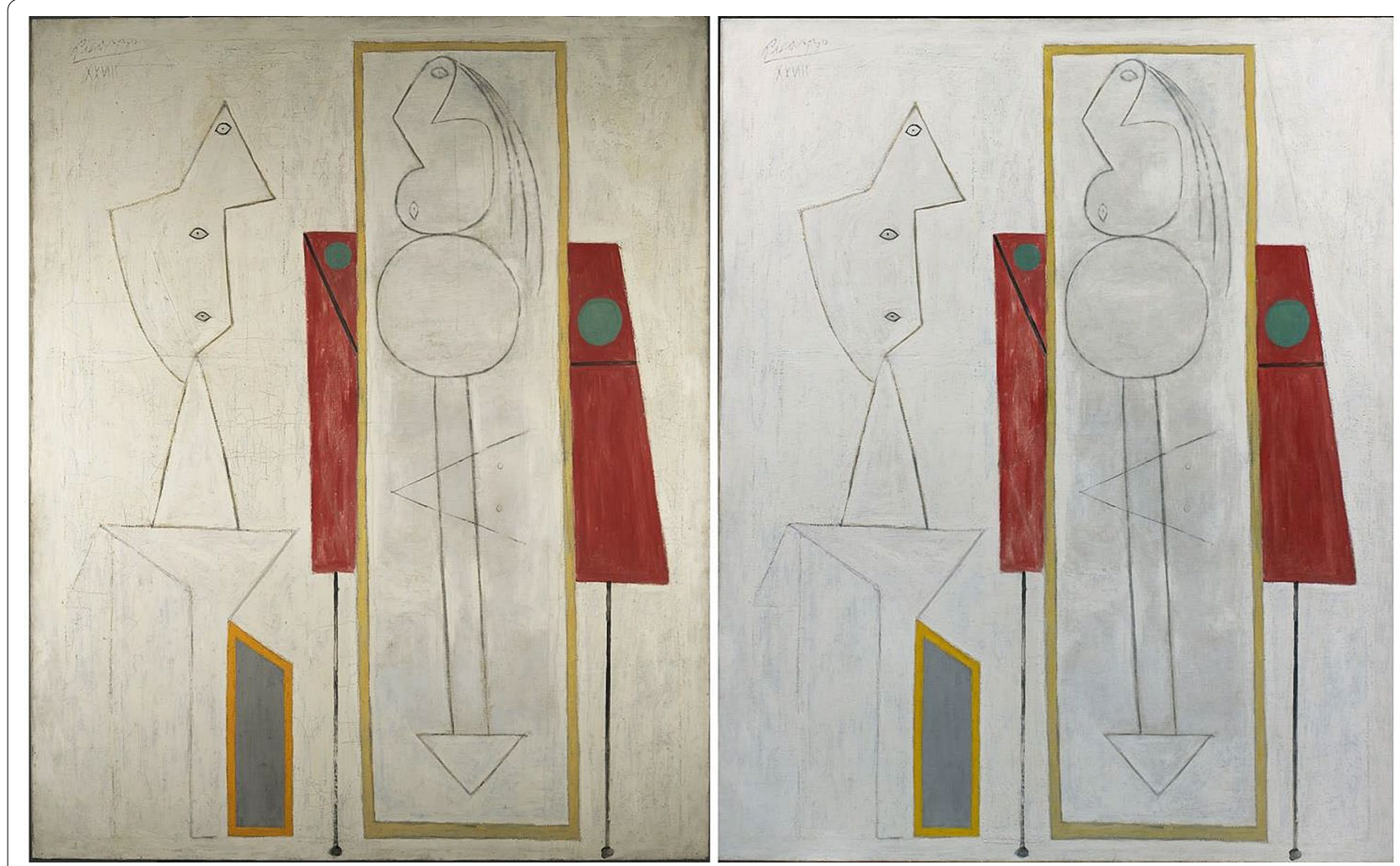

Fig. 1 Pablo Picasso, The Studio ("L'Atelier"), 1928, Peggy Guggenheim Collection, Venice (The Solomon R. Guggenheim Foundation, New York), before (left) and after (right) the cleaning carried out with TC-PN hydrogels loaded with the O/W NSF. OSuccession Picasso, by SIAE 2020 


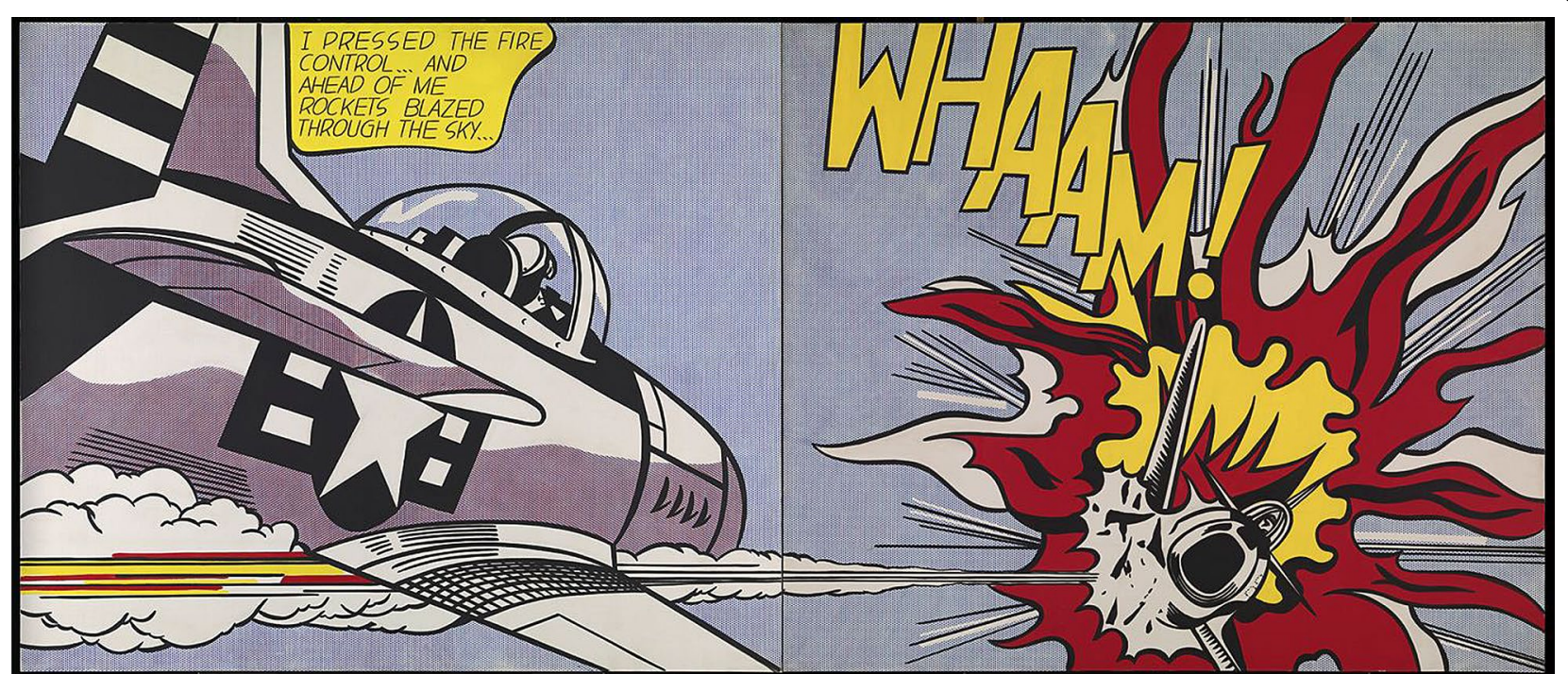

Fig. 2 Roy Lichtenstein's Whaam! during cleaning. The difference between the left (cleaned) and right (yet to be cleaned) panels is evident. Photo @Tate 2017; @The estate of Roy Lichtenstein

T02394) [4]. After extensive testing, the surface of the artifact's top papier mâché was cleaned applying an aqueous solution with cosmetic sponges, while the sculpture ropes were cleaned using tailored formulations of hydrogels based on networks of PVA semi-interpenetrated with polyvinyl pyrrolidone (PVP), so as to obtain low-risk and effective recovery of the artifact's aesthetics (Fig. 3).

The conservation of the supports of painted artifacts is also addressed, as illustrated by three papers included in the selection [5-7]. The first paper reports on the development and evaluation of sustainable treatments for the consolidation of canvasses in modern and contemporary art [5]. Namely, both polar and nonpolar formulations were developed by mixing deacidification agents (sub$\mu \mathrm{m}$-particles of calcium carbonate or magnesium oxide) with either polar (hydroxyethyl methyl cellulose and nanocrystalline cellulose) or nonpolar components (sylilated cellulose), and using water or heptane as dispersing media. The application of these products to aged and degraded canvas showed good increase of breaking force with only low mass uptake and slight optical changes. The deacidification results in the deposition of an alkaline reserve that prevents recurring degradation. The second paper evaluates consolidants and deacidifying agents based on different nanoparticles (silica, calcium carbonate, magnesium oxide, cellulose nanofibrils and cellulose nanocrystals) as compared to traditional products, monitoring color, gloss and $\mathrm{pH}$ changes [6]. The best performing novel formulations were those based on calcium carbonate, magnesium oxide and cellulose nanocrystals. Cellulose nanofibrils are also promising consolidants given their physico-chemical compatibility with painting canvasses. The authors of the third paper carried out the systematic mechanical assessment of consolidants for canvas reinforcement under controlled environment [7]. The newly developed consolidant based on nanofibrillated cellulose (CNF) was compared to commonly used natural and synthetic adhesives, checking the visual appearance, consolidation effect, and response of the mechanical properties of the treated canvases to programmed changes in relative humidity $(\mathrm{RH})$. The consolidants form bridges between the cotton fibers, whereas the CNF treatment formed a visible continuous and dense surface coating. No significant color change was observed. Treatment with CNF produced a higher value of Young's modulus than the traditional products. Besides, the dynamic mode mechanical testing showed that the nanofibrillated cellulose treatment led to the highest variation in storage (or elastic) modulus measured at the end of RH plateaux ( 20 and $80 \% \mathrm{RH}$ ). These results candidate CNF as a promising material for the consolidation of canvasses.

Moving to different types of artistic substrates, a paper by Mirabile et al. provides a critical overview and expansion on the use of two novel methodologies for the removal of pressure sensitive tapes (PSTs), which employ different cleaning fluids loaded into retentive gels [8]. Essentially, hydrogels loaded with an o/w NSF and organogels loaded with a green alkyl carbonate solvent represent two complementary approaches that altogether allow the removal of different classes of tapes from sensitive paper artworks. Thanks to the retentiveness of the 


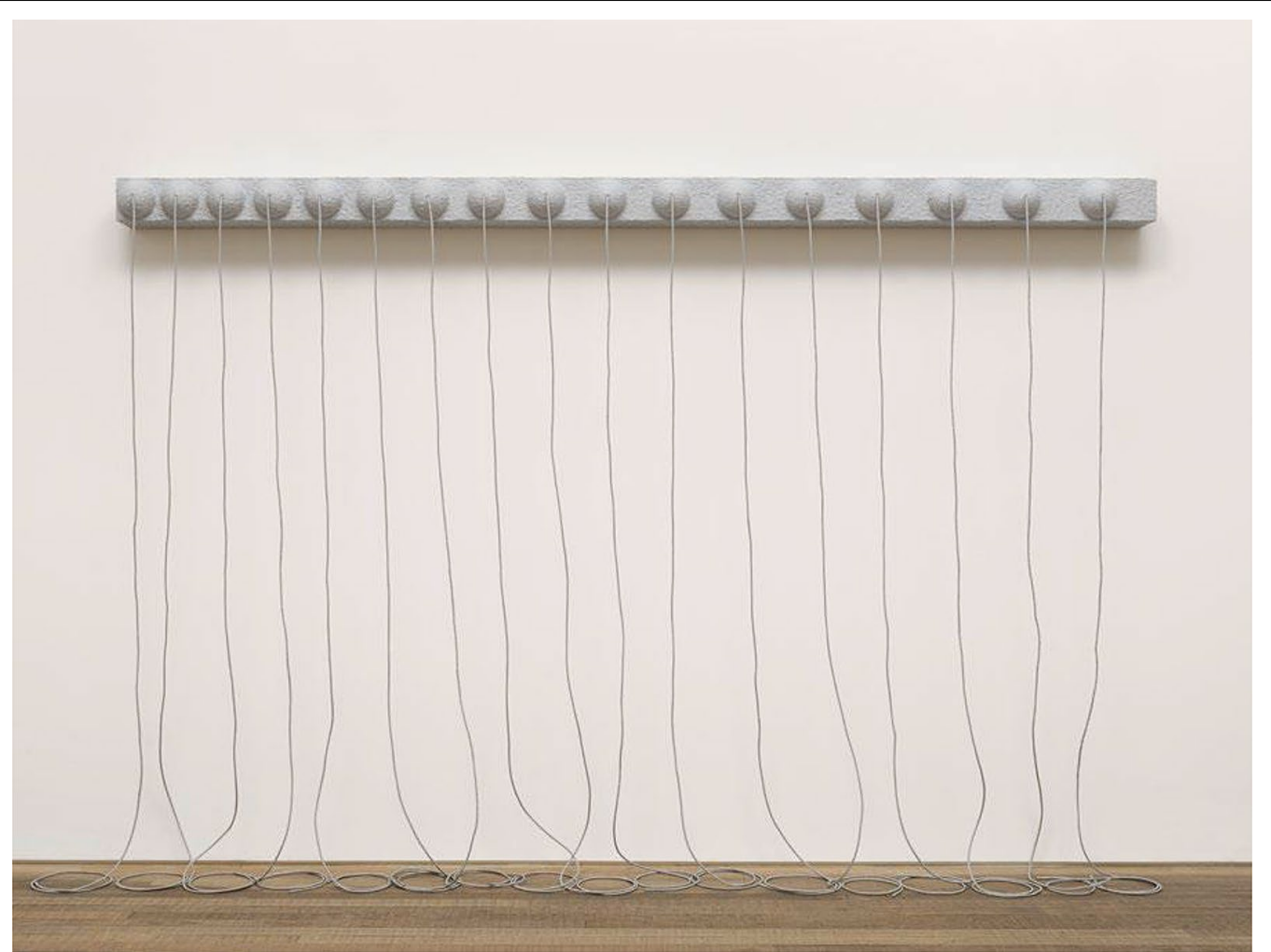

Fig. 3 Eva Hesse's Addendum after cleaning and on display at Tate Modern. Photo Tate, July $2018 \odot$ The estate of Eva Hesse, courtesy Hauser \& Wirth, Zürich

gels, both methods permit selective PST removal without uncontrolled inks bleeding or matter transport through the paper matrix. An inclusive assessment was carried out on four completely different paper artworks, where the new formulations proved to be versatile tools to either remove aged PSTs or re-adhere detackified tapes that were part of the original artwork.

The protection of metal surfaces is addressed in a paper by da Conceicão et al., which evaluated the potential of a hybrid system made by an imidazolium salt (as an anticorrosion additive) and chitosan-based coatings for the protection of copper-based alloys [9]. The best performances under accelerated corrosion conditions were exhibited by a combination of the imidazolium salt with benzotriazole (whose toxicity is decreased by confinement into the chitosan matrix), which granted optimal protective efficacy of the bronze surface without changing the metal appearance.

Finally, advanced detection tools for the analysis of modern artworks are discussed in a paper by Aylami et al. [10]. Surface Enhanced Raman Scattering (SERS) is a powerful tool for the identification of dyes, but its application in real case studies is limited by its inherent invasiveness and the need of extracting samples. Instead, the paper proposes non-invasive transparent SERS probes fabricated by self-assembly of $\mathrm{Ag}$ nanoparticles into glass and polydimethylsiloxane (PDMS) surfaces. SERS measurements can be carried out directly on selected surfaces using these probes, which are then removed with no contamination of the surfaces. Identification of dyes on a ballpoint drawing and a Japanese woodblock print confirmed the potential of this diagnostic methodology.

Overall, the selection of papers demonstrates a palette of new exciting and sustainable tools for the restoration and analysis of modern and contemporary artifacts, opening new perspectives and setting new standards in the field of $\mathrm{CH}$ preservation.

\section{Acknowledgements}

All NANORESTART partners are gratefully acknowledged for their contribution to the project results. The European Union Horizon 2020 project NANORESTART (Nanomaterials for the Restoration of Works of Art), under the Horizon 2020 Research and Innovation Programme Grant Agreement 646063, is gratefully acknowledged for the financial support. The authors also acknowledge Richard Brereton and Matthew Smyllie for their support and assistance during the editing and production of this issue. 


\section{Authors' contributions}

All authors contributed equally to the writing of this manuscript. All authors read and approved the final manuscript.

\section{Funding}

The research carried out in NANORESTART (Nanomaterials for the Restoration of Works of Art) has received funding from the European Union under the Horizon 2020 Research and Innovation Programme Grant Agreement 646063.

\section{Availability of data and materials}

Not applicable.

\section{Competing interests}

The authors declare that they have no competing interests.

Received: 15 December 2020 Accepted: 18 December 2020

Published online: 11 January 2021

\section{References}

1. Baij L, Hermans J, Ormsby B, Noble P, ledema P, Keune K. A review of solvent action on oil paint. Herit Sci. 2020;8:43.

2. Pensabene Buemi L, Petruzzellis ML, Chelazzi D, Baglioni M, Mastrangelo R, Giorgi R, Baglioni P. Twin-chain polymer networs loaded with nanostructured fluids for the removal of a non-original varnish from Picasso's "L'Atelier" at the Peggy Guggenheim Collection. Venice Herit Sci. 2020;8:77.

3. Bartoletti A, Barker R, Chelazzi D, Bonelli N, Baglioni P, Lee J, Angelova LV, Ormsby B. Reviving WHAAM! a comparative evaluation of cleaning systems for the conservation treatment of Roy Lichtenstein's iconic painting. Herit Sci. 2020;8:9.
4. Bartoletti A, Maor T, Chelazzi D, Bonelli N, Baglioni P, Angelova LV, Ormsby B. Facilitating the conservation treatment of Eva Hesse's Addendum through practice-based research, including a comparative evaluation of novel cleaning systems. Herit Sci. 2020;8:35.

5. Böhme N, Anders M, Rechelt T, Schuhmann K, Bridarolli A, Chevalier A. New treatments for canvas consolidation and conservation. Herit Sci. 2020;8:16.

6. Oriola-Folch M, Campo-Francés G, Nualart-Torroja A, Ruiz-Recases C, Bautista-Morenilla I. Novel nanomaterials to stabilize the canvas support of paintings assessed from a conservator's point of view. Herit Sci. 2020;8:23.

7. Bridarolli A, Nualart-Torroja A, Chevalier A, Odlyha M, Bozec L. Systematic mechanical assessment of consolidants for canvas reinforcement under controlled environment. Herit Sci. 2020:8:52.

8. A Mirabile, D Chelazzi, P Ferrari, C montis, D Berti, N Bonelli, R Giorgi, P Baglioni. Innovative methods for the removal, and occasionally care, of pressure sensitive adhesive tapes from contemporary drawings. Herit Sci 2020. 8;42

9. Silva da Conceicão DK, Nunes de Almeida K, Nhuch E, Raucci MG, Santillo C, Salzano de Luna M, Ambrosio L, Lavorgna M, Giuliani C, Di Carlo G, Staccioli MP, Falcade T, Schrekker HS. The synergistic effect of an imidazolium salt and benzotriazole on the protection of bronze surfaces with chitosan-based coatings. Herit Sci. 2020;8:40

10. Alyami A, Mirabile A, lacopino D. Fabrication of transparent composites for non-invasive Surface Enhanced Raman Scattering (SERS) analysis of modern art works. Herit Sci. 2020;7:87.

\section{Publisher's Note}

Springer Nature remains neutral with regard to jurisdictional claims in published maps and institutional affiliations.

\section{Submit your manuscript to a SpringerOpen ${ }^{\circ}$ journal and benefit from:}

- Convenient online submission

- Rigorous peer review

- Open access: articles freely available online

- High visibility within the field

- Retaining the copyright to your article

Submit your next manuscript at $\boldsymbol{\nabla}$ springeropen.com 